\title{
Impaired glucose tolerance (IGT) is associated with reduced insulin-induced suppression of glucagon concentrations
}

\author{
B. Ahrén, H. Larsson \\ Department of Medicine, Lund University, Lund, Sweden
}

\section{Abstract}

Aims/hypothesis. We aimed to examine whether impaired glucose tolerance is associated with reduced suppression of glucagon concentrations.

Methods. Eighty-four non-diabetic women of Caucasian origin and 61 years of age, of whom 48 had normal glucose tolerance (NGT) and 36 had IGT, underwent a 75 g OGTT and a hyperinsulinaemic, euglycaemic clamp with measurement of glucagon, insulin and glucose concentrations.

Results. At $2 \mathrm{~h}$ after $75 \mathrm{~g}$ oral glucose, glucagon concentrations were reduced by $7.1 \pm 1.1 \mathrm{ng} / \mathrm{l}$ in NGT vs $8.0 \pm 1.4 \mathrm{ng} / \mathrm{l}$ in IGT, (NS). However, the $2 \mathrm{~h}$ reductions in glucagon per $\mathrm{mmol} / \mathrm{l}$ increase in $2 \mathrm{~h}$ glucose or per pmol/l increase in $2 \mathrm{~h}$ insulin were both impaired in IGT ( $p=0.002$ and $p=0.043$, respectively) because the $2 \mathrm{~h}$ increases in glucose and insulin were higher in IGT than in NGT. Furthermore, suppression of glucagon concentrations during a euglycaemic clamp at hyperinsulinaemic concentrations (NGT: $607 \pm 19$ pmol/l, IGT: $561 \pm 21 \mathrm{pmol} / \mathrm{l})$ was lower in IGT $(13.6 \pm 1.6 \mathrm{ng} / \mathrm{l})$ than in NGT $(23.1 \pm 1.2 \mathrm{ng} / \mathrm{l}$; $p<0.001)$. The suppression of glucagon concentrations during the hyperinsulinaemic, euglycaemic clamp correlated with insulin sensitivity $(r=0.24$, $p=0.027)$ and with the $2 \mathrm{~h}$ glucose value during the OGTT $(r=-0.52, p<0.001)$.

Conclusion/interpretation. Impaired glucose tolerance is associated with reduced insulin-induced suppression of glucagon secretion, which could be caused by A-cell insulin resistance. Inappropriately high glucagon secretion could therefore contribute to the metabolic perturbations in IGT. [Diabetologia (2001) 44: 1998-2003]

Keywords Glucagon secretion, suppression, impaired glucose tolerance, IGT, Type II diabetes, insulin clamp, OGTT, humans.
Type II (non-insulin-dependent) diabetes mellitus is associated with increased hepatic glucose production which is linked to fasting hyperglycaemia [1-3]. This could be explained by glucagon, because along with impairment in insulin action and insulin secretion diabetic patients also have reduced suppression of glucagon secretion [4-7]. Reduced suppression of glucagon has, furthermore, been shown to contribute to postprandial hyperglycaemia in Type II diabetic pa-

Received: 15 May 2001 and in revised form: 13 July 2001

Corresponding author: Dr. Bo Ahrén, Department of Medicine, Lund University, B11 BMC, SE-221 84 LUND, Sweden, e-mail: Bo.Ahren@med.lu.se tients [8]. Similarly, lack of suppression of glucagon during glucose administration increases the hyperglycaemia in non-diabetic subjects [9] as well as in patients with Type I (insulin-dependent) diabetes mellitus [10]. We have recently shown that subjects with impaired glucose tolerance (IGT) show increased glucagon secretion in response to an arginine challenge at high glucose [11] and that increased glucagon concentrations predict worsening of glucose tolerance in non-diabetic subjects [12]. Furthermore, reduced suppression of glucagon during OGTT testing has been observed in subjects with IGT [13]. Inappropriately high glucagon concentrations and reduced suppression of glucagon could therefore be involved in the metabolic perturbations in diabetic patients 
and in subjects with increased risk for developing diabetes, in conjunction with impaired insulin secretion. The inappropriately high glucagon concentrations could be explained by the reduced ability of insulin to inhibit glucagon secretion as a sign of insulin resistance in the A cells [14]. We explored this possibility by examining whether subjects with IGT or NGT show different suppression of glucagon concentrations during an OGTT and during a hyperinsulinaemic, euglycaemic clamp.

\section{Subjects and methods}

Study design. Oral glucose tolerance tests and euglycaemic hyperinsulinaemic clamps [15] were carried out in 84 non-diabetic female subjects of Caucasian origin, all 61 years of age. Both studies were done in the morning after an overnight fast with at least one week between the visits. The ethics committe of Lund University approved the study and informed written consent was obtained from all participants before entry into the study.

Subjects. 84 participants were recruited from a larger cohort of 841 postmenopausal women living in the city of Malmö, Sweden who participate in a health screening which identifyed that $27 \%$ of the subjects had IGT [16]. The subjects were randomly selected from their $2 \mathrm{~h}$ glucose concentration at an oral glucose tolerance; 48 had NGT and 36 had IGT. All 84 subjects were healthy and none were taking any medication known to affect carbohydrate metabolism (Table 1).

Oral glucose tolerance test. An intravenous catheter was inserted into an antecubital vein. After a baseline sample, an oral glucose tolerance test was carried out as a standard WHO 75 g glucose load [18]. Blood samples were taken before and at 30, 60, 90 and 120 min after the oral glucose ingestion. The subjects spent the two hours in a semi-recumbent position.

Hyperinsulinaemic, euglycaemic clamp. Insulin sensitivity was measured with the euglycaemic, hyperinsulinaemic clamp as described previously [15]. Intravenous catheters were inserted into antecubital veins in both arms. One arm was used for infusion of glucose and insulin; the contralateral arm was used for intermittent sampling. After obtaining two baseline samples, a primed-constant infusion of insulin (Actrapid $100 \mathrm{U} / \mathrm{ml}$, Novo Nordisk, Bagsvaerd, Denmark) with a constant infusion rate of $0.28 \mathrm{nmol} / \mathrm{m}^{2}$ body surface area per min was started. After $4 \mathrm{~min}$, a variable rate $20 \%$ glucose infusion was added and its infusion rate was adjusted manually throughout the clamp procedure to maintain the blood glucose concentration at $5.0 \mathrm{mmol} / \mathrm{l}$. Blood glucose was measured at the participants' bedside every $5 \mathrm{~min}$. Mean blood glucose during the second hour of the clamp test was $5.1 \pm 0.1$ (means \pm SEM) $\mathrm{mmol} / \mathrm{l}$. Samples for analysis of insulin and glucagon were taken at 0 , 60 and 120 minutes.

Analyses. Blood glucose concentration was measured from the patients at their bedside by the glucose dehydrogenase technique with an Accutrend ${ }^{\circledR}$ (Boehringer Mannheim Scandinavia AB, Bromma, Sweden). Blood samples for analysis of glucagon, insulin and glucose were immediately centrifuged at $5{ }^{\circ} \mathrm{C}$ and serum or plasma frozen at $-20^{\circ} \mathrm{C}$ until analysis in
Table 1. Characteristics of the 84 women examined divided into the two groups of normal glucose tolerance (NGT) and impaired glucose tolerance (IGT)

\begin{tabular}{|c|c|c|c|}
\hline Variable & $\begin{array}{l}\text { NGT } \\
(n=48)\end{array}$ & $p$ & $\begin{array}{l}\text { IGT } \\
(n=36)\end{array}$ \\
\hline Age & $\begin{array}{l}61 \text { year } \\
10 \pm 5 \text { mo }\end{array}$ & NS & $\begin{array}{l}61 \text { year } \\
8 \pm 5 \mathrm{mo}\end{array}$ \\
\hline Body mass index $\left(\mathrm{kg} / \mathrm{m}^{2}\right)$ & $25.4 \pm 3.5$ & NS & $25.8 \pm 3.3$ \\
\hline Waist circumference $(\mathrm{cm})$ & $81.5 \pm 9.1$ & NS & $83.4 \pm 8.3$ \\
\hline $\begin{array}{l}\text { Fasting blood glucose } \\
(\mathrm{mmol} / \mathrm{l})\end{array}$ & $4.7 \pm 0.6$ & 0.005 & $5.1 \pm 0.8$ \\
\hline $2 \mathrm{~h}$ blood glucose $(\mathrm{mmol} / \mathrm{l})$ & $6.5 \pm 0.8$ & $<0.001$ & $9.0 \pm 0.1$ \\
\hline $\begin{array}{l}\Delta \mathrm{AUC}_{\text {glucose }}(\mathrm{mmol} / \mathrm{l} \mathrm{x} \\
120 \mathrm{~min})\end{array}$ & $174 \pm 88$ & $<0.001$ & $333 \pm 126$ \\
\hline Fasting serum insulin (pmol/l) & $78 \pm 25$ & 0.045 & $91 \pm 34$ \\
\hline 30 min serum insulin (pmol/l) & $496 \pm 46$ & $<0.001$ & $352 \pm 43$ \\
\hline $\begin{array}{l}30 \mathrm{~min} \text { insulin response } \\
(\mathrm{pmol} / \mathrm{l})\end{array}$ & $418 \pm 32$ & $<0.001$ & $261 \pm 36$ \\
\hline$\Delta \mathrm{AUC}_{\text {insulin }}(\mathrm{nmol} / \mathrm{l} \times 120 \mathrm{~min})$ & $42.9 \pm 27.9$ & NS & $41.9 \pm 21.2$ \\
\hline Fasting plasma glucagon (ng/l) & $52.1 \pm 3.7$ & NS & $49.2 \pm 2.7$ \\
\hline$\Delta \mathrm{AUC}_{\text {glucagon }}(\mathrm{ng} / \mathrm{l} \times 120 \mathrm{~min})$ & $-547 \pm 127$ & NS & $-553 \pm 129$ \\
\hline $\begin{array}{l}\text { Fasting plasma cholesterol } \\
(\mathrm{mmol} / \mathrm{l})\end{array}$ & $5.9 \pm 0.9$ & NS & $6.1 \pm 1.1$ \\
\hline $\begin{array}{l}\text { Fasting plasma triglycerides } \\
(\mathrm{mmol} / \mathrm{l})\end{array}$ & $1.2 \pm 0.6$ & 0.021 & $1.5 \pm 0.6$ \\
\hline
\end{tabular}

Insulin sensitivity (nmol

glucose $\cdot \mathrm{kg}$ body weight ${ }^{-1}$.

minute $^{-1} / \mathrm{pmol}$ insulin $\left.\cdot \mathrm{l}^{-1}\right) \quad 75.6 \pm 28 \quad 0.046 \quad 62.3 \pm 24$

$\triangle \mathrm{AUC}$ indicates the area under the curve from baseline value. Means \pm SD are shown. $p$ indicates probability of random difference between the groups

duplicate. Plasma glucagon was measured with double-antibody radioimmunoassay in duplicate using guinea pig antihuman glucagon antibodies specific for pancreatic glucagon, ${ }^{125}$ I-glucagon as tracer and glucagon standard (Linco Research, St Charles, Mo., USA). Serum insulin concentrations were analysed with double-antibody RIA technique using guinea pig anti-human insulin antibodies, human insulin standard and mono- ${ }^{125}$ I-Tyr-human insulin (Linco). Plasma glucose concentrations were analysed using the glucose oxidase method. All concentrations were taken as means of the duplicate samples.

Calculations. Data are given as means \pm SEM, unless otherwise noted. Suppression of glucagon during the OGTT was calculated as the difference between glucagon concentrations at time 0 and $120 \mathrm{~min}$. This difference was also divided by the change in glucose or insulin concentrations during the $2 \mathrm{~h}$ to evaluate the reduction in glucagon concentrations per increased $\mathrm{mmol} / \mathrm{l}$ glucose or $\mathrm{pmol} / \mathrm{l}$ insulin. The suprabasal or subbasal areas under the curve (AUC) during the $2 \mathrm{~h}$ OGTT were also calculated for glucose, insulin and glucagon using the trapezoid rule. Suppression of glucagon during the hyperinsulinaemic, euglycaemic clamp was calculated as the difference in glucagon concentrations at time 0 vs the mean at 60 and $120 \mathrm{~min}$. Insulin sensitivity (nmol glucose $\cdot \mathrm{kg}$ body weight ${ }^{-1} \cdot \min ^{-1} / \mathrm{pmol}$ insulin $\cdot 1^{-1}$ ) was calculated as glucose infusion rate divided by the mean insulin at 60 and $120 \mathrm{~min}$ [15]. 

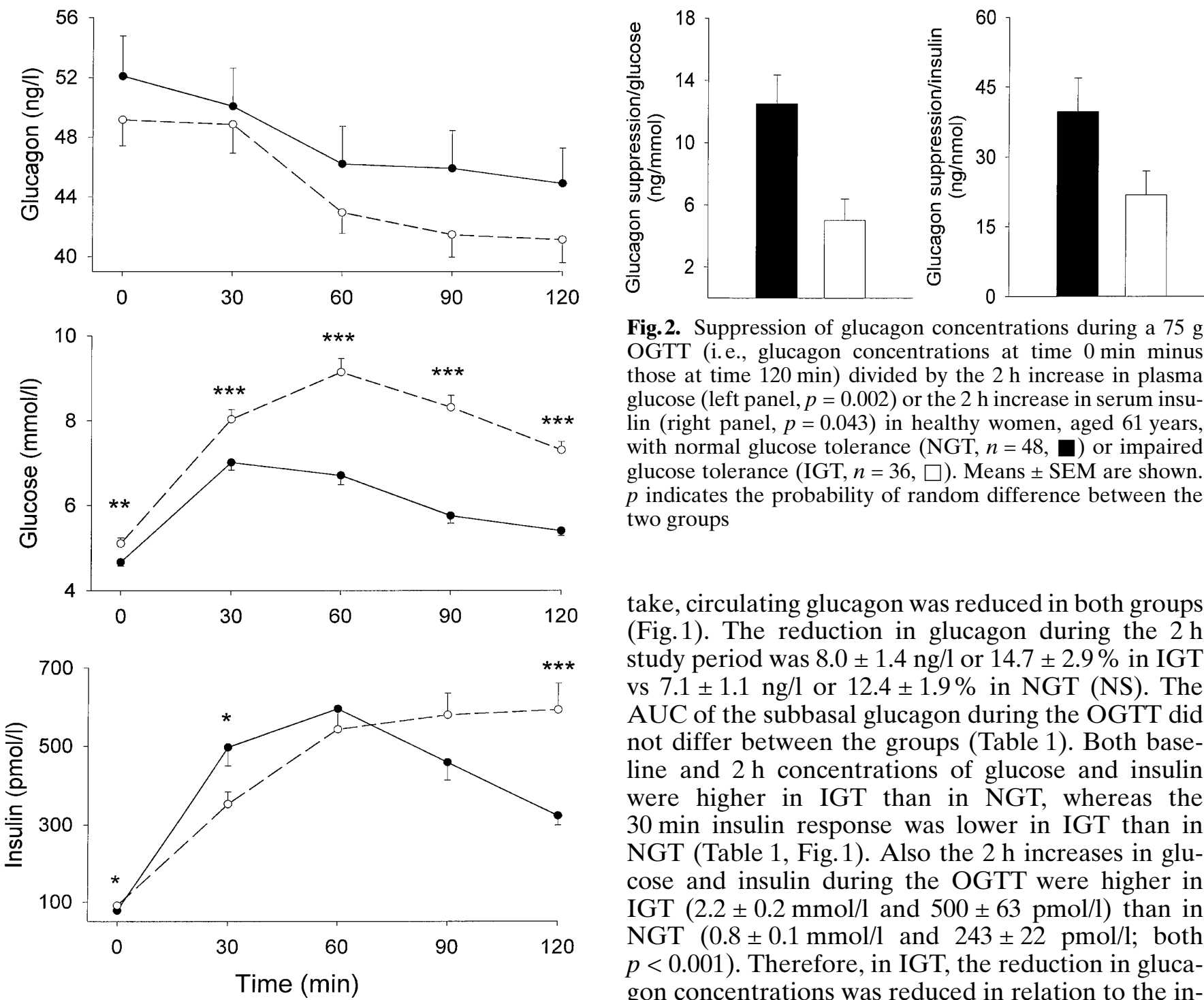

Fig. 2. Suppression of glucagon concentrations during a $75 \mathrm{~g}$ OGTT (i.e., glucagon concentrations at time 0 min minus those at time $120 \mathrm{~min}$ ) divided by the $2 \mathrm{~h}$ increase in plasma glucose (left panel, $p=0.002$ ) or the $2 \mathrm{~h}$ increase in serum insulin (right panel, $p=0.043$ ) in healthy women, aged 61 years, with normal glucose tolerance (NGT, $n=48, \mathbf{\square})$ or impaired glucose tolerance (IGT, $n=36, \square$ ). Means \pm SEM are shown. $p$ indicates the probability of random difference between the two groups

take, circulating glucagon was reduced in both groups (Fig.1). The reduction in glucagon during the $2 \mathrm{~h}$ study period was $8.0 \pm 1.4 \mathrm{ng} / \mathrm{l}$ or $14.7 \pm 2.9 \%$ in IGT vs $7.1 \pm 1.1 \mathrm{ng} / \mathrm{l}$ or $12.4 \pm 1.9 \%$ in NGT $(\mathrm{NS})$. The AUC of the subbasal glucagon during the OGTT did not differ between the groups (Table 1). Both baseline and $2 \mathrm{~h}$ concentrations of glucose and insulin were higher in IGT than in NGT, whereas the 30 min insulin response was lower in IGT than in NGT (Table 1, Fig.1). Also the $2 \mathrm{~h}$ increases in glucose and insulin during the OGTT were higher in IGT $(2.2 \pm 0.2 \mathrm{mmol} / 1$ and $500 \pm 63 \mathrm{pmol} / \mathrm{l})$ than in NGT $(0.8 \pm 0.1 \mathrm{mmol} / \mathrm{l}$ and $243 \pm 22 \mathrm{pmol} / \mathrm{l}$; both $p<0.001)$. Therefore, in IGT, the reduction in glucagon concentrations was reduced in relation to the increases in glucose and insulin as judged by dividing the $2 \mathrm{~h}$ suppression of glucagon with the $2 \mathrm{~h}$ increase

Fig. 1. Plasma concentrations of glucagon and glucose and serum insulin during a $75 \mathrm{~g}$ OGTT in healthy women, aged 61 years, with normal glucose tolerance (NGT, $n=48,-\bullet$ ) or impaired glucose tolerance (IGT, $n=36,-\circ)$. Means \pm SEM are shown. Asterisks indicate the probability of random difference between the two groups; $* p<0.05,{ }^{*} p<0.01$, $* * * p<0.001$

Statistics. Statistical analyses were done with the SPSS for Windows system (SPSS Inc., Chicago, Il., USA). Mann-Whitney U test was used for testing differences between the groups. Spearman regression coefficients were obtained to estimate correlation. Linear stepwise forward multiple regression was used to assess the independent effect of several variables. A probability of random difference of $p$ less than 0.05 was considered to be statistically significant.

\section{Results}

Glucagon and insulin responses to oral glucose. Baseline glucagon did not differ significantly between IGT and NGT (Table 1). After the $75 \mathrm{~g}$ oral glucose inin glucose $(p=0.002)$ and in insulin $(p=0.043$; Fig. 2). In contrast, when dividing the suppression of glucagon concentrations by the $30 \mathrm{~min}$ insulin concentration no difference between the groups was observed.

Glucagon response during hyperinsulinaemic, euglycaemic clamp. During the steady state second hour of the hyperinsulinaemic, euglycaemic clamp, insulin concentrations were $561 \pm 21 \mathrm{pmol} / 1$ in IGT vs $607 \pm 19 \mathrm{pmol} / \mathrm{l}$ in NGT. Baseline glucagon did not differ between the groups but during the hyperinsulinaemic, euglycaemic clamp study, glucagon concentrations were higher in IGT $(37.3 \pm 1.8 \mathrm{ng} / \mathrm{l})$ than in NGT $(28.7 \pm 2.5 \mathrm{ng} / \mathrm{l} ; p=0.007$, Fig. 3$)$. The suppression of glucagon during the clamp was therefore reduced in subjects with IGT $(13.6 \pm 1.6 \mathrm{ng} / \mathrm{l})$ compared to NGT $(23.1 \pm 1.2 \mathrm{ng} / \mathrm{l} ; p<0.001$, Fig. 3$)$. Also the insulin sensitivity, as measured by the hyperinsulinaemic, euglycaemic clamp, was lower in IGT than in 

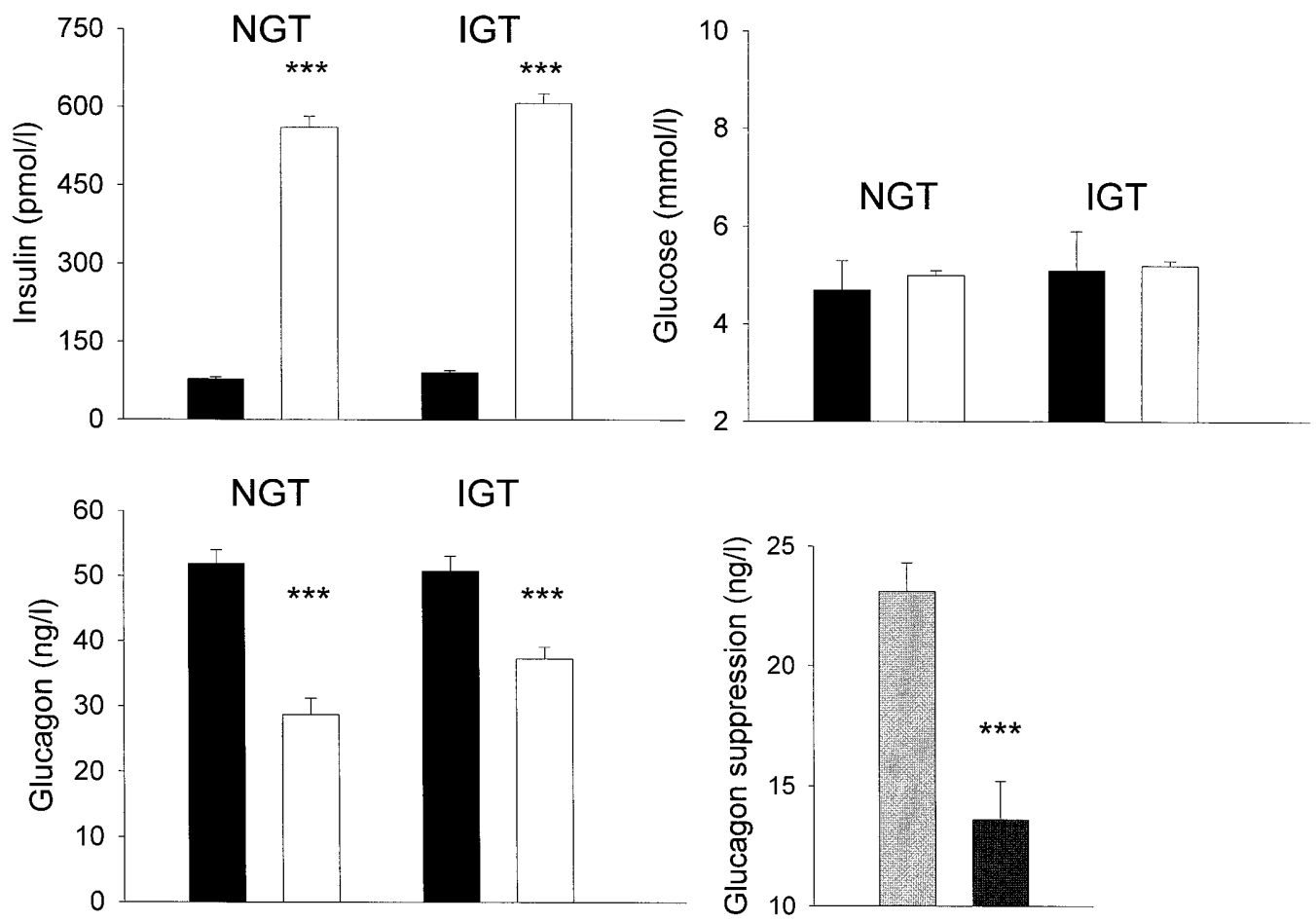

Fig.3. Fasting serum insulin, plasma glucose and plasma glucagon before the euglycaemic, hyperinsulinaemic clamp (a) vs the mean of the 60 and 120 min values during the clamp $(\square)$ in healthy women, aged 61 years, with normal glucose tolerance (NGT, $n=48$ ) or impaired glucose tolerance (IGT, $n=36$ ). Lower right (NGT, $n=48$, $\square$, IGT, $n=36$, 口) shows the difference between the glucagon concentrations before and during the clamp, i.e., the suppression of glucagon concentrations. Means \pm SEM are shown. Asterisks indicate the probability of random difference during the clamp; $* * * p<0.001$

Table 2. Stepwise forward multiple regression model to determine whether suppression of glucagon concentrations during hyperinsulinaemic, euglycaemic, clamp and insulin sensitivity was the best predictor of the $2 \mathrm{~h}$ glucose value during an oral glucose tolerance test in 84 non-diabetic women, aged 61

\begin{tabular}{llllll}
\hline Step & Variable & B & SE (B) & $r$ & $p$ \\
\hline 1 & Suppression of glucagon & 0.21 & 0.03 & -0.50 & $<0.001$ \\
2 & Insulin sensitivity & 0.036 & 0.004 & -0.64 & $<0.001$ \\
\hline
\end{tabular}

NGT ( $p=0.046$, Table 1$)$. The suppression of glucagon correlated significantly with the insulin sensitivity $(r=0.24, p=0.027)$. Both the suppression of glucagon during the clamp $(r=-0.52, p<0.001)$ and insulin sensitivity $(r=-0.50 ; p<0.001)$ correlated negatively to the $2 \mathrm{~h}$ glucose concentration in the OGTT. A multivariate stepwise analysis with the $2 \mathrm{~h}$ glucose concentration as the independent variable and the suppression of glucagon during the clamp and the insulin sensitivity as independent variables showed that both these variables significantly and independently predicted the $2 \mathrm{~h}$ glucose value (Table 2 , $r=-0.64, p<0.001)$.

\section{Discussion}

In patients with Type II diabetes, glucagon concentrations are usually increased [4-7] and suppression of glucagon concentrations reduces glycaemia after food intake [8]. This would support that agents inhibiting glucagon secretion or counteracting glucagon action might be beneficial for patients with diabetes [18]. This has been reinforced by animal studies showing that immunoneutralization of glucagon by a specific antiserum lowers circulating glucose in fed rats [19], in rats subjected to neonatal administration of streptozotocin [20] and in alloxan-diabetic rabbits [21].

We have previously shown that subjects with IGT have increased glucagon secretory response to iv arginine at high glucose and that this augmentation predicts future deterioration of glucose tolerance $[11,12]$, suggesting augmented A-cell responsiveness in IGT. We examined the suppressibility of glucagon in IGT and found that the reduction of glucagon concentrations during OGTT was not significantly different in subjects with IGT compared with subjects with NGT. This would suggest that suppression of glucagon concentrations is not altered in IGT. However, as both $2 \mathrm{~h}$ glucose and $2 \mathrm{~h}$ insulin concentrations were higher in IGT than in NGT, a larger suppression of glucagon concentrations would be anticipated in IGT. Since this was not observed, we conclude that the suppression of glucagon concentrations is reduced in IGT. When the suppression of glucagon concentrations was divided by the increased glucose and insulin concentrations, significantly lower suppression was evident in IGT. This confirms the previous 
observation that the insulin to glucagon ratio after oral glucose was substantially higher in subjects with IGT than in subjects with NGT [13]. Hence, lack of appropriate suppression of glucagon, as in Type II diabetes [8] is also evident in subjects at risk of developing diabetes.

The subjects with IGT had significantly higher fasting insulin concentrations than the subjects with NGT, which suggests that they had reduced insulin sensitivity, which was supported by the results of the hyperinsulinaemic, euglycaemic clamp. Also the initial $30 \mathrm{~min}$ rise in insulin was lower in the subjects with IGT, despite a higher glucose concentration at this time point. This confirms a previous study that defective early insulin response to glucose is a characteristic of subjects with IGT [13]. Following this early phase after oral glucose, plasma insulin concentrations were higher in the subjects with IGT. The $2 \mathrm{~h}$ plasma insulin concentrations correlated with the $2 \mathrm{~h}$ glucose value $(r=0.64, p<0.001)$ which supports that it is the achieved higher glucose concentrations which cause the $2 \mathrm{~h}$ hyperinsulinemia. This supports the hypothesis that a primary defect in IGT is a defective early insulin response which results in inappropriately high glucose concentrations which in turn augments insulin secretion during the later time points of the test $[13,22,23]$. Also the defective relative suppression of glucagon concentrations might contribute to the high $2 \mathrm{~h}$ glucose concentration by augmenting the release of glucose into the circulation [13]. This is supported by the studies in non-diabetic subjects showing that lack of suppression of glucagon results in hyperglycaemia when insulin secretion is impaired [10]. Hence, the impaired glucose tolerance seems to be caused by a combination of defective early insulin response in combination with defective glucagon suppression. Whether the slight reduction in insulin sensitivity, which supports previous reports in IGT [24,25], also contributes to the perturbations or whether it is caused by the hyperglycaemia and hyperinsulinemia can not be established from this cross sectional study.

The mechanism of the defective suppression of glucagon secretion in IGT is not known. An important factor to inhibit glucagon secretion is insulin through activation of insulin receptors on the A cells [26-28]. Since the subjects with IGT had whole body insulin resistance, the impaired suppression of glucagon observed in these subjects might be explained by insulin resistance at the level of the A cell. We examined this possibility by measuring glucagon during the hyperinsulinaemic, euglycaemic clamp, i.e., a condition in which circulating insulin was raised to a similar concentration in the two groups. We found that the reduction in glucagon concentrations during the hyperinsulinaemic clamp was impaired in IGT. The results therefore suggest that a failure to suppress glucagon secretion in IGT is dependent on a rel- ative inability of insulin to inhibit the A cells. This is further supported by the correlation between insulin sensitivity and suppression of glucagon during the hyperinsulinaemic, euglycaemic clamp. Inability of insulin to suppress glucagon in IGT might also explain the increased glucagon response to arginine in IGT, as previously reported [11], because arginine elicits a strong insulin secretory response which will tend to counteract the direct action of arginine to stimulate glucagon secretion.

Of interest, the suppression of glucagon concentrations during the hyperinsulinaemic, euglycaemic clamp correlated negatively to the $2 \mathrm{~h}$ glucose concentration in the OGTT and was, in association with the reduced insulin sensitivity, an independent predictor of the $2 \mathrm{~h}$ glucose concentration in a multivariate analysis. This further suggests that defective glucagon suppression contributes to the metabolic perturbations in IGT.

Our results show that the inability of insulin to suppress glucagon concentrations is evident at an early stage during the development of Type II diabetes and it could be caused by A-cell insulin resistance. This supports a strategy of developing agents which inhibit glucagon secretion or counteract glucagon action for the early treatment of diabetes.

Acknowledgements. The authors are grateful to L. Bengtsson, L. Bryngelsson, U. Gustavsson, K. Nilsson and M. Persson for expert technical assistance. The study was supported by the Swedish Medical Research Council (6834), Novo Nordisk Foundation, the Swedish Diabetes Association, Malmö University Hospital and the Faculty of Medicine, Lund University.

\section{References}

1. DeFronzo RA (1988) The triumvirate: $\beta$-cell, muscle, liver. A collusion responsible for NIDDM. Diabetes 37: 667-687

2. Tappy L (1995) Regulation of hepatic glucose production in healthy subjects and patients with non-insulin-dependent diabetes melliuts. Diabet Metab 21: 233-240

3. Gerich JE (1996) Pathogenesis and treatment of type 2 (noninsulin-dependent) diabetes mellitus (NIDDM). Horm Metab Res 28: 404-412

4. Muller WA, Faloona GR, Aguilar-Parada E, Unger RH (1970) Abnormal $\alpha$-cell function in diabetes. N Engl J Med 283: 109-115

5. Reaven GM, Chen YD, Golay A, Swislocki AL, Jaspan JB (1987) Documentation of hyperglucagonemia throughout the day in nonobese and obese patients with noninsulin-dependent diabetes mellitus. J Clin Endocrinol Metab 64: 106-110

6. Dimitriadis GD, Pehling GD, Gerich JE (1985) Abnormal glucose modulation of islet $\mathrm{A}$ - and $\mathrm{B}$-cell responses to arginine in non-insulin-dependent diabetes mellitus. Diabetes 34: $541-547$

7. Baron AD, Schaeffer L, Shragg P, Kolterman OG (1987) Role of hyperglucagonemia in maintenance of increased rates of hepatic glucose output in type II diabetics. Diabetes 36: 274-283 
8. Shah P, Vella A, Basu A, Basu R, Schwenk WF, Rizza RA (2000) Lack of suppression of glucagon contributes to postprandial hyperglycaemia in subjects with type 2 diabetes mellitus. J Clin Endocrinol Metab 85: 4053-4059

9. Shah P, Basu A, Basu R, Rizza R (1999) Impact of lack of suppression of glucagon on glucose tolerance in humans. Am J Physiol 277: E283-E290

10. Dinneen S, Alzaid A, Turk D, Rizza R (1995) Failure of glucagon suppression contributes to postprandial hyperglycaemia in IDDM. Diabetologia 38: 337-343

11. Larsson H, Ahrén B (2000) Islet dysfunction in insulin resistance involves impaired insulin secretion and increased glucagon secretion in postmenopausal women with impaired glucose tolerance. Diabetes Care 23: 650-657

12. Larsson H, Ahrén B (2000) Glucose intolerance is predicted by low insulin secretion and high glucagon secretion: outcome of a prospective study in postmenopausal Caucasian women. Diabetologia 43: 194-202

13. Mitrakou A, Kelley D, Mokan M et al. (1992) Role of reduced suppression of glucose production and diminished early insulin release in impaired glucose tolerance. $\mathrm{N}$ Engl J Med 326: 22-29

14. Ipp E (2000) Impaired glucose tolerance: the irrepressible alpha cell. Diabetes Care 23: 569-570

15. DeFronzo RA, Tobin JD, Andres R (1979) Glucose clamp technique: a method for quantifying insulin secretion and resistance. Am J Physiol 237: E214-E223

16. Larsson H, Ahrén B, Lindgärde F, Berglund G (1995) Fasting blood glucose in determining prevalence of diabetes in a large, homogenous population of Caucasian middle-aged women. J Intern Med 237: 537-541

17. World Health Organization (1985) Diabetes mellitus: Report of a WHO Study Group. WHO Technical Report Series No 75, World Health Organization, Geneva

18. Madsen P, Brand CL, Holst JJ, Knudsen B (1999) Advances in non-peptide glucagon receptor antagonists. Curr Pharm Des 5: 683-691
19. Brand CL, Jørgensen PN, Knigge U et al. (1995) Role of glucagon in maintenance of euglycemia in fed and fasted rats. Am J Physiol 269: E469-E477

20. Brand CL, Rolin B, Jørgensen PN, Svendsen I. Kristensen JS, Holst JJ (1994) Immunoneutralization of endogenous glucagon with monoclonal glucagon antibody normalizes hyperglycaemia in moderately streptozotocin-diabetic rats. Diabetologia 37: 985-993

21. Brand CL, Jørgensen PN, Svendsen I, Holst JJ (1996) Evidence for a major role for glucagon in regulation of plasma glucose in conscious, nondiabetic, and alloxan-induced diabetic rabbits. Diabetes 45: 1076-1083

22. Perley MJ, Kipnis DM (1967) Plasma insulin responses to oral and intravenous glucose: studies in normal and diabetic subjects. J Clin Invest 46: 1954-1962

23. Gerich JE (1998) The genetic basis of type 2 diabetes mellitus: impaired insulin secretion versus impaired insulin sensitivity. Endocr Rev 19: 491-503

24. Lillioja S, Mott DM, Spraul M et al. (1993) Insulin resistance and insulin secretory dysfunction as precursors of non-insulin-dependent diabetes mellitus: prospective studies of Pima Indians. N Engl J Med 329: 1988-1992

25. Haffner SM, Miettinen H, Gaskill SP, Stern MP (1996) Decreased insulin action and insulin secretion predict the development of impaired glucose tolerance. Diabetologia 39: 1201-1207

26. Van Schravendijk CF, Foriers A, Hooghe-Peters EL et al. (1985) Pancreatic hormone receptors on islet cells. Endocrinology 117: 841-848

27. Kisanuki K, Kishikawa H, Araki E et al. (1995) Expression of insulin receptor on clonal pancreatic alpha cells and its possible role for insulin-stimulated negative regulation of glucagon secretion. Diabetologia 38: 422-429

28. Fehmann HC, Strowski M, Lankat-Buttgereit B, Göke B (1994) Molecular and functional characterization of insulin receptors present on hamster glucagonoma cells. Digestion 55: $214-220$ 